\title{
ARGENTINISMOS EN EL LÉXICO DEL ESPAÑOL DE CHILE: NUEVAS EVIDENCIAS
}

\author{
ARGENTINISMS IN THE LEXICON OF CHILEAN \\ SPANISH: NEW EVIDENCE
}

\section{GASTÓN SALAMANCA* Y ARIELLA RAMÍREZ**}

\section{RESUMEN}

Este artículo constituye una continuación de los "Apuntes sociolingüísticos sobre la presencia de argentinismos en el léxico del español de Chile" (Salamanca, 2010). Se presentan en él 10 palabras que, de acuerdo con los criterios adoptados, tienen una alta probabilidad de ser argentinismos presentes en el léxico del español de Chile. Las páginas introductorias y el marco de referencia sitúan este estudio en el contexto de los trabajos sobre la influencia que ha recibido el léxico del español de Chile (concretamente, los trabajos sobre indigenismos y anglicismos). En la sección dedicada a los aspectos metodológicos, se explicita la manera de constituir el corpus y el procedimiento seguido para establecer el estatus de argentinismo de cada enunciado. El apartado siguiente ("Argentinismos") presenta las 10 palabras seleccionadas, con las respectivas evidencias para asignarles el estatus de argentinismos/lunfardismos. La última sección contiene algunas interpretaciones y proyecciones a partir de los resultados de los análisis. De ellas se desprende que el proceso de argentinización cultural, en general, y lingüístico, en particular, es un fenómeno rastreable históricamente y muy vigente en la actualidad.

Palabras clave: Sociolingüística, español de Chile, argentinismos.

\section{ABSTRACT}

The present article is the continuation of "Apuntes sociolingüísticos sobre la presencia de argentinismos en el léxico del español de Chile" (Salamanca, 2010). Ten new words

* Doctor en Lingüística. Profesor Depto. de Español, Universidad de Concepción. Concepción, Chile E-mail: gaston.salamanca@gmail.com

** Licenciada en Educación con mención en Español. E-mail: ariella.ramirez.correa@gmail.com 
which have been identified as highly likely to be Argentinisms or Lunfardisms in Chilean Spanish are identified. The introduction and theoretical framework situate this study within the context of studies of loan words in Chilean Spanish (specifically, those dealing with loans from indigenous languages and from English). The methodology section describes the creation of the corpus and the procedures used to detect Argentinisms. The next section presents the 10 words identified as Argentinisms, and provides evidence for this classification in each case. The final section provides interpretations of the results and projections based on them, and concludes that the general process of cultural Argentinization, and the specific process of linguistic Argentinization, are historicallytraceable phenomena that continue to operate in contemporary Chile.

Keywords: Sociolinguistics, Chilean Spanish, argentinisms.

Recibido: 12.11.13. Aceptado: 03.01.14.

\section{INTRODUCCIÓN}

$\mathrm{E}$ L ESTUDIO DE LA INFLUENCia que ha recibido el léxico del español de Chile se ha focalizado hasta ahora, fundamentalmente, en dos frentes: el sustrato indígena y la influencia del inglés. Respecto del primer foco, Adalberto Salas (1992) tiene una tesis radical, que se resume en que "ninguna sociedad aborigen actualmente viviente tuvo oportunidad histórica de incidir en la lengua y la cultura de Chile" (Salas, 1992: 15), restándole plausibilidad a la tesis, también radical, de Rodolfo Lenz sobre la decisiva influencia del mapuche en la formación de la pronunciación chilena. En efecto, Salas señala que una influencia significativa de esta lengua en el léxico del español de Chile debiera verse reflejada en una buena cantidad de mapuchismos antiguos y asentados en él, lo que es muy diferente de lo que efectivamente ocurre: escaso léxico mapuche $-y$ de circulación más bien restringida $-\mathrm{y}$ trivial desde el punto de vista cultural.

En relación con el segundo foco, Sáez (1999) describe el panorama que se vive en Chile a fines del siglo veinte. Se refiere a un proceso de constante globalización e internacionalización de las relaciones de los hablantes chilenos con la comunidad global, sobre todo porque las comunicaciones de todo tipo son, en esta parte de la historia, más masivas y accesibles a los hablantes del español de nuestro país. Precisamente, prosigue este autor, a través de esta fluidez en las comunicaciones llega a nuestro país mayor variedad de contenido, lo que se traduce en una ventana hacia las culturas de otros países. Es así como llega la influencia de un país que tiene un alto prestigio entre los hablantes chilenos, como es los Estados Unidos. Según Sáez (1999: 46), primero llegan los léxicos técnicos, los cuales pronto van 
siendo asimilados e integrados al hablar cotidiano. Quienes están más susceptibles a la anglosajonización -más específicamente, "estadounización"del lenguaje son los hablantes jóvenes, los que integran estos léxicos a la conversación coloquial juvenil y, posteriormente, a la lengua común informal.

Estos son los dos focos atendidos de manera preferente por la literatura que versa sobre la influencia que ha recibido el español de Chile. Sin embargo, en nuestros días se puede advertir una creciente influencia léxica de un país vecino: Argentina. Decimos "creciente" porque esta influencia no sólo ocurre en los años recientes, sino que es un fenómeno rastreable históricamente ${ }^{1}$, tal como lo comprueba la presencia de palabras como "mina", "gil", "cafiche", entre otras, en el léxico del español de Chile.

En su trabajo de 2010, Salamanca se ocupa de manera sistemática de esta influencia en nuestra variante del español, utilizando para ello dos ejes descriptivos: las nociones de "prestigio encubierto" y "permeabilidad asimétrica". En nuestro artículo se concuerda con la afirmación propuesta por este autor, en cuanto a que la cantidad de ejemplos que él examina en absoluto agotan los casos en que es posible rastrear esta influencia.

Un trabajo de muy reciente aparición, que se vincula directamente con el tema que nos ocupa es "Voces de origen lunfardo en el registro festivo del diario chileno La Cuarta" (San Martín, 2011). Su propósito fue "establecer, cuantitativa y cualitativamente, el carácter que asume la presencia de voces de origen lunfardo en el léxico empleado en el registro festivo del diario chileno La Cuarta". Concretamente, se intentó, con éxito,

determinar la participación de los lunfardismos en los procesos de cambio semántico, formación léxica y fijación fraseológica, implicados en una muestra de quince ejemplares del mencionado periódico (aproximadamente 375 páginas) aparecidos entre noviembre y diciembre de 1998 y entre mayo y junio de 2004 (San Martín, 2011: 105).

Un aporte sustantivo de este trabajo es el inventario lexicográfico de los lunfardismos relevados, en el cual se señalan la caracterización gramatical, la definición de acepciones y los ejemplos de uso de cada voz o locución relevada en el corpus.

\footnotetext{
${ }^{1}$ Una de las vías de ingreso en las generaciones pasadas fue la música tradicional de Buenos Aires (tango y milonga). También es posible advertir una influencia de la música popular argentina de los años 70 en adelante sobre la juventud chilena de esos períodos. Sin embargo, a diferencia del tango y la milonga, no es del todo claro que este último influjo se haya plasmado en un registro léxico perdurable.
} 
El trabajo que presentamos complementa los hallazgos de Salamanca (2010), así como la presentación de San Martín (2011), pues presenta 10 (nuevas) palabras que tienen una alta probabilidad de ser etiquetadas como argentinismos presentes en el léxico del español de Chile ${ }^{2}$. Se utiliza para ello una metodología de análisis y un formato de exposición de los resultados similar a la que se presenta en el primer trabajo referido.

\section{MARCO DE REFERENCIA}

\subsection{Sociolingüística, lengua y dialecto}

Esta investigación se inserta en el ámbito de la Sociolingüística. De acuerdo con Silva-Corvalán (2001), la principal ocupación de esta interdisciplina es identificar procesos de cambio lingüístico en marcha y establecer los límites sociales de ciertos usos lingüísticos, sobre todo investigando en centros urbanos caracterizados por su heterogeneidad lingüística y social.

Dado que lo que se aborda en nuestro artículo es la influencia de un dialecto del español en otro -del español de Argentina en el español de Chile-, se precisa de una definición técnica de "dialecto". Para Silva-Corvalán, este término "se refiere simplemente a una variedad de lengua compartida por una comunidad" (2001: 14), independientemente de su mayor o menor prestigio social. Entre las causas del desarrollo de diferentes dialectos de una lengua están los movimientos migratorios, la colonización y el contacto con otras lenguas ya existentes. Los ejemplos más obvios de esta variación dialectal están en la pronunciación y el léxico. Por ejemplo, la migración masiva de italianos a Argentina introdujo palabras de uso cotidiano en la vida diaria como "pibe" por "niño", "nono/a" por "abuelo/a", "laburo" por "trabajo", las cuales establecen una diferencia con otras variedades del español (Silva-Corvalán, 2001: 15).

Por otro lado, es interesante la pregunta que se plantea Salas (1996) en cuanto al estatus de lenguas -o dialectos- del mapuche, el aymara y el pascuense. Para responder a esta pregunta explica qué atributos hacen a una lengua ser una lengua, y también cómo la percepción popular juega en con-

\footnotetext{
${ }^{2}$ Hablamos aquí de "alta probabilidad" y no de una comprobación categórica y definitiva, pues para ello tendríamos que establecer el día y hora precisos en que esta palabra comenzó a usarse en ambos países, cuestión que, si acaso es una empresa posible, está fuera de las pretensiones de nuestro trabajo.
} 
tra de ellas, restándoles su calidad de tal. Para referirse a este último punto, contrasta el pensamiento popular y lo que establecen las ciencias sociales. Así, de acuerdo con el pensamiento popular, para que un sistema de comunicación tenga la categoría de "lengua" tiene que cumplir con ciertos atributos, tales como sonidos bien articulados, representación gráfica (sistema de escritura), estudio y enseñanza en instancias formales de educación, gramática compleja, vocabulario rico que permita su incursión en la cultura "civilizada" y tener destacados protagonistas que participen de la cultura a lo largo de la historia (Salas, 1996: 27). De acuerdo con esta concepción popular, las lenguas vernáculas no entrarían en la categoría de "lengua"; por consiguiente, lo que los indígenas hablarían no serían más que dialectos.

Sin embargo, para las ciencias sociales, la palabra "cultura" incluye todo el comportamiento humano socialmente aprendido, en oposición a aquella parte genéticamente heredada: "Esto significa que toda forma de comportamiento humano que requiera saber, es cultural" (Salas, 1996: 28). Por lo tanto, ejercitar este saber en el diseño, fabricación o uso de un producto es cultura. Para el cientista social, en consecuencia, los enunciados "cultura aymara", "cultura mapuche", "cultura pascuense", etc., están llenos de un sentido que motiva su estudio, pues, indudablemente, y como señala este autor, "los grupos indígenas tienen su lengua y su cultura, diferentes a otras lenguas y otras culturas, pero diferente sólo en la superficie externa" (Salas, 1996: 29-30). En efecto, todas las lenguas humanas poseen los atributos de dualidad de pauta, gramaticalidad y multimodalidad, y, por ello, funcionan con el mismo potencial comunicativo, independientemente del nivel de desarrollo científico y tecnológico que tengan quienes las hablan. En otras palabras, como destaca el propio Salas (1996: 36), toda lengua se manifiesta en dialectos y todo dialecto lo es de una lengua, de modo que podemos hablar con toda propiedad de dialectos del inglés, el alemán y el español, así como de una lengua mapuche, aymara y pascuense.

\subsection{Sustrato indigena, anglicismos y argentinismos en el español de Chile}

\subsubsection{Sustrato indígena}

Como hemos señalado, Adalberto Salas (1992) postula que ninguna de las sociedades indígenas actualmente vivas ha tenido oportunidad histórica de influir en la lengua y cultura de Chile, ya que los pueblos indoamericanos de presencia antigua, como los diaguitas y mapuches del norte de Chile, 
habrían desaparecido durante el periodo de formación de la nacionalidad y mucho antes del advenimiento de la República. Propone que nuestra lengua y cultura son parte de la lengua y cultura de los conquistadores y colonizadores, o sea, lengua española y cultura cristiana. Aun cuando la resistencia mapuche en el sur de Chile ha sido fuerte, claramente su lengua no es vista, desde el pensamiento europeo de nuestros antepasados, con el prestigio suficiente como para adoptarla como propia. Para Salas, por lo tanto, la tesis que propuso Rodolfo Lenz sobre la influencia decisiva del mapuche en la formación de la pronunciación chilena no tiene plausibilidad, pues, como declara:

Sea por una razón (predominio poblacional hispanohablante nativo) o sea por otra (operación decisiva de factores socioculturales hispanizantes), o por una combinación de ambas, el hecho objetivo es que la lengua mapuche no ha tenido incidencia en la formación de la pronunciación chilena del castellano, al menos en el nivel segmental (Salas, 1992: 17).

Si fuera real la incidencia del mapuche en nuestra variante del español, prosigue este autor, se reflejaría en un amplio repertorio de mapuchismos antiguos y asentados en el léxico del español de Chile. Sin embargo, esta influencia es cuantitativa y cualitativamente baja: "hay pocos mapuchismos y casi todos ellos son de frecuencia baja, de circulación restringida, esporádicos, ocasionales y, más bien, triviales desde el punto de vista cultural" (Salas, 1992: 17). En efecto, prosigue Salas, la mayoría de las palabras de origen mapuche existentes son topónimos y nombres de la naturaleza (flora, fauna y paisaje) y sólo estarían informándonos que en el Reino de Chile, entre el Valle del Elqui y la Isla grande de Chiloé, la población autóctona hablaba mapuche. Así, basado en todo lo expuesto, concluye que el componente indoamericano en la identidad sociocultural chilena es mínimo³.

\subsubsection{Anglicismos}

Con respecto al segundo aspecto de influencia sobre nuestra variante del español, Sáez (2000) constata la fuerte presencia de anglicismos en el léxico

\footnotetext{
${ }^{3}$ Con esto no niega la posibilidad de que el mestizaje tenga un sustento biológico consistente, lo que sí niega es que "tenga consecuencias en la lengua y cultura verbalizada por los chilenos. Esto significa que aunque la investigación en historia y antropología física demuestre que en el Reino de Chile hubo un mestizaje hispano-mapuche masivo, consistente y prolongado, en la práctica seguirá siendo irrelevante para la dimensión sociocultural” (Salas, 1992: 19).
} 
del español de Chile. Este autor señala que el primer estudio en esta línea fue realizado en 1942 por la alemana Gabriele Schwarzhaupt. Para ella, la mayor incidencia de la cultura inglesa en nuestra variante del español está en los campos del deporte, la navegación y el vestuario, en tanto que la influencia de la cultura norteamericana se centra en los tecnicismos, la industria y en el léxico juvenil, a través de las fiestas, bailes, modas, cine, etc.

El mismo Sáez ya en su trabajo de 1999 había descrito el panorama que se vive en Chile al llegar al siglo XX como un proceso constante de globalización e internacionalización de todo tipo: hay mayor posibilidad de viajar al extranjero y de que los extranjeros vengan a Chile, hay mayor conectividad por internet, TV cable y satelital, y, gracias a esto, podemos ver programación de otros países y continentes. Estos hechos tendrían consecuencias lingüísticas, ya que a través de los medios globalizados nuestra variante del español de Chile se vería afectada por la influencia de otros dialectos (Sáez, 1999: 18).

La introducción de anglicismos en los léxicos especializados, que luego se trasladan al habla cotidiana, es una de las consecuencias que el autor considera importante, al punto que ha logrado documentar más de tres mil voces entre anglicismos crudos, adaptaciones, traducciones, calcos semánticos y variantes, señalando que se agregan entre diez a quince cada semana. Esta presencia está más marcada en los léxicos computacionales, musicales, deportivos, de administración de empresas, vestuario y publicitario.

\subsection{Argentinismos en el español de Chile}

De acuerdo con Salamanca (2010), la relación que se da entre la variante del español de Chile y la variante del español de Argentina es particularmente interesante, ya que el chilenohablante tiene, en general, una imagen desmejorada respecto de "lo argentino", actitud que se refleja en las reacciones públicas frecuentes de desaprobación hacia quienes poseen esta nacionalidad. Sin embargo, el aporte léxico de la variante argentina a la variante chilena es destacable, razón por la cual el autor etiqueta esta situación como "prestigio encubierto". Destaca, también, que esta permeabilidad no es recíproca, sino asimétrica, pues, por ejemplo, cuando se entrevista a argentinos que están radicados en Chile, se comprueba que no han perdido las características fonéticas, gramaticales y/o léxicas prominentes de su variante del español.

En relación con esta permeabilidad, señala también que es transdiastrática y transetaria. Con respecto a la primera, señala que la influencia del 
léxico argentino permea los distintos estratos socioculturales en Chile. Por ejemplo, el léxico argentino permea el léxico del estrato sociocultural alto a través de dos vías: a) su difusión en pubs, playas, etc., durante la temporada estival ${ }^{4}$ y b) su difusión a través de los viajes que los chilenos realizan a ese país cada vez con mayor frecuencia. El léxico del estrato sociocultural medio, a su vez, es influenciado a través de dos vías: a) la televisión por cable ${ }^{5}$, donde se muestran actitudes, palabras y modismos que se presentan en el fútbol argentino, los cuales se traspasan después al fútbol chileno y b) la presencia permanente de argentino(a)s en programas de televisión abierta (principalmente aquellos del género realities). La influencia en el léxico del estrato sociocultural bajo, por su parte, se produce fundamentalmente a través de la llamada cumbia villera.

Con respecto a la segunda característica -permeabilidad transdiastrática-, menciona que la permeabilidad no se restringe sólo a la población adulta, sino que ocurre también en el segmento más joven en Chile.

Es interesante señalar que, en general, el chilenohablante considera que la mayoría de estas palabras pertenecen al acervo de chilenismos y no está consciente de que son préstamos provenientes del país transandino.

San Martín (2011), por su parte, destaca la clara participación del lunfardo en los recursos de creación léxica en La Cuarta, ya sea a través de cambios semánticos (como en las palabras mino, pulento, tortazo y tocomocho) o como base para la generación de nuevas palabras (como minita, bacancito, puchito). Repara, también, en "las sugerentes apreciaciones de Salamanca (2010: 149) quien destaca la 'permeabilidad asimétrica' que existe entre el léxico de origen argentino y chileno" (San Martín, 2011: 145). Por último, subraya que las voces de origen lunfardo empleadas en los ejemplares de este diario son utilizadas en el habla popular chilena (como bacán, cana, luca, mina, rajado y como la mona): "Respecto de esta influencia del léxico argentino en el chileno, resulta sintomático el hecho de que en un medio como La Cuarta se emplee una cantidad considerable de voces de origen lunfardo, debido precisamente a su perfil como 'diario popular'” (San Martín, 2011: 145).

\footnotetext{
${ }^{4}$ En este período de alta afluencia de turistas argentinos a Chile, estos lugares se constituyen en centros de irradiación cultural.

${ }^{5}$ Accesible hoy prácticamente a todos los estratos socioculturales en Chile.
} 


\section{ASPECTOS METODOLÓGICOS}

\subsection{El corpus}

Esta investigación se inicia con el acopio de un grupo de enunciados que forman parte del léxico informal de Chile y Argentina. El acceso a estos enunciados se efectuó a través de la lectura de la prensa y el visionado de programas de televisión de ambos países. De aquí surgieron las primeras hipótesis sobre la permeabilidad de nuestra variante, con respecto a la variante hablada en Argentina. Después de registrar un número superior a 30 enunciados "sospechosos" de constituir argentinismos presentes en el léxico del español de Chile, se refinó el corpus, de modo que, de acuerdo con el grado de simetría en la forma y el significado de los enunciados, su frecuencia, y su alcance transdiastrático y transetario, el corpus final quedó constituido por 18 palabras. Ahora, al constatar que 8 de estas palabras coincidían con las que se presentan en el recientísimo trabajo de San Martín (2011) (engrupir, laburo, chamullar, piola, cana, lanza, rasca, (meter la) mula), redujimos esta presentación a 10 de ellas.

\subsection{Procedimiento para establecer el estatus de argentinismo del enunciado}

El foco del procedimiento utilizado para establecer el estatus de argentinismo de cada palabra consistió en su detección en distintas recopilaciones de léxico lunfardo ${ }^{6}$. De estas recopilaciones, por su rigor y cobertura, se seleccionaron como fuentes más confiables el Nuevo diccionario lunfardo (Gobello, 1999) y el Diccionario del lunfardo (Espíndola, 2002), de modo que la presencia de una palabra en estos dos registros fue interpretada como indicador de una alta probabilidad de que la palabra fuera un argentinismo importado al léxico del español de Chile. Cabe destacar que estos diccionarios no sólo dan cuenta de la presencia de estas palabras en el léxico lunfardo, sino que, en la mayoría de los casos, muestran la clara vinculación de éste con el léxico proveniente de Italia (específicamente, del genovés). Por últi-

${ }^{6}$ El Diccionario de la Real Academia Española define el "lunfardo" como el "Habla que originariamente empleaba, en la ciudad de Buenos Aires y sus alrededores, la gente de clase baja. Parte de sus vocablos y locuciones se introdujeron posteriormente en la lengua popular y se difundieron en el español de la Argentina y el Uruguay" (http://buscon.rae.es/draeI/SrvltConsulta?TIPO_ BUS=3\&LEMA=lunfardo). 
mo, a través de cuentos, novelas, letras de canciones, etc., estos diccionarios muestran la temprana data de uso de estas palabras en el país trasandino.

Por otro lado, y como complemento a este procedimiento, se buscó la palabra en cuestión en el Diccionario de la Real Academia Española (en adelante, $D R A E$ ), pues en algunos casos esta fuente explicita el uso de esta palabra en el Río de la Plata y/o en Chile, aunque, por cierto, sin especificar la direccionalidad de la importación léxica.

Finalmente, y con todos los resguardos que esto supone, buscamos el ítem en cuestión en Wikcionario ${ }^{7}$, pues en muchas ocasiones las descripciones que allí se contienen añaden algunas consideraciones o ejemplos interesantes a aquellos que se presentan en las fuentes que hemos considerado como primarias.

\section{ARGENTINISMOS ${ }^{8}$}

Presentamos a continuación 10 palabras que estimamos tienen una alta probabilidad de ser consideradas argentinismos (lunfardismos) presentes en el léxico del español de Chile. En cada uno de estos casos, se propone que la fecha en que se constata su uso en Argentina es anterior a la fecha en que el uso de esa misma palabra se difunde en Chile?

\section{1) Canchero}

El Diccionario del lunfardo define esta palabra como:

[...] Conocedor de las cosas de la vida y la naturaleza humana// Dominador de cualquier situación [...]. (Espíndola, 2002: 101).

\footnotetext{
${ }^{7}$ Disponible en: http://es.wiktionary.org/wiki/Main_Page

${ }^{8}$ Hemos utilizado negritas para destacar las palabras estudiadas -incluso en los textos citados- y alguna información particularmente relevante sobre el lugar o fecha de origen de dichas palabras.

${ }^{9}$ Tres razones respaldan esta asunción: a) no se encontró evidencia del uso de esa palabra antes o durante la misma fecha en Chile, b) los resultados de una entrevista informal a sujetos hablantes nativos de la variante hablada en Chile muestran, consistentemente, que la fecha en que éstos estiman se comenzó a utilizar esta palabra en este país es siempre posterior a la fecha en que se reporta su uso en Argentina y c) la alta permeabilidad que exhibe el español de Chile, en contraste con la escasa permeabilidad de la variante argentina.
} 
Consigna, también, la presencia de esta palabra en el verso de un poema que data de 1928 (La excanchera, de Carlos de la Púa):

[...] La mina obligada de todos los púas / La criolla canchera, fiel del arrabal / La que despreciaba el oro del magnate / La paica de ley [...].

El Nuevo diccionario lunfardo, por su parte, indica:

v. CANCHA. [...]Que muestra constante dominio de las situaciones (“... con seguridad de tipo canchero". Gómez Bas, La comparsa, 105). (Gobello, 1999: 53-54).

En el DRAE no se consigna esta palabra.

Los siguientes ejemplos extraídos de la prensa nacional confirman su difusión en el español de Chile actual:

-Por canchero Leonardo Trigo cayó chanchito, gracias a la tecnología policial, en un motel de Valparaíso (Pie de foto) ${ }^{10}$

-Camiroaga llegó canchero y le lindorfeó a la Tía Coty ${ }^{11}$

\section{2) Chau}

El Diccionario del lunfardo señala:

Lunf. Hasta luego. Hasta pronto. Adiós. Saludo de despedida [...]. De origen dialectal italiano [...]. (Espíndola, 2002: 123).

El Nuevo Diccionario Lunfardo, por su parte, indica:

Lunf. Adiós. Fórmula de saludo [...]. (Gobello, 1999: 83).

Consigna, también, la presencia de esta palabra en una novela que data del año 1953 (Calles de tango, de Bernardo Verbitsky, p. 36): "Me tomo éste que me deja en la puerta. Chau. Mañana nos vemos".

\footnotetext{
${ }^{10} \mathrm{http}: / /$ www.cuarta.cl/diario/2006/05/13/13.03.4a.CRO.PARRILLA.html

11 http://www.lacuarta.cl/noticias/espectacular/2009/11/65-66646-9-camiroaga-llego-cancheroy-le-lindorfeo-a-la-tia-coty.shtml 12 de febrero de 2010.
} 
En Wikcionario se presenta un resumen de la etimología de esta palabra $^{12}$ :

Etimología: Es muy interesante que esta forma súbita de despedirse tenga vínculo con la esclavitud: la clave es el término italiano 'schiavo', que en la antigua Italia era un particular modo de decir adiós. Es similar a lo acontecido en el castellano con 'servidor', que se emplea para señalar cortésmente que está a disposición de otros. Ese tratamiento subsiste en la fórmula Su seguro servidor, clásico cierre de ciertas cartas formales. En algunos países europeos se dice servus, siervo, con igual sentido. Con el tiempo, schiavo pasó abreviado a ciao (ciau, en genovés) y llegó a Uruguay y a Argentina como chau: despedida informal. Chau agrega énfasis al adiós $[\ldots]$.

El DRAE consigna su presencia en Argentina y Uruguay, entre otros países sudamericanos, pero no en Chile:

1. interj. coloq. Arg., Bol., Perú y Ur. $\underline{\text { chao }}^{13}$

Sin embargo, los siguientes ejemplos extraídos de un portal de Internet y de la prensa nacional, respectivamente, confirman su difusión en el español de Chile actual:

-Fiesta “Chau PSU”. Martes 2 de Diciembre. Espacio Riesco ${ }^{14}$

-Cabros trabajan con cototo sistema informático y aprenden al toque ¡Chau, cuadernos! Peñalolén enseña con PDA ${ }^{15}$

\section{3) Gauchada}

El Diccionario del lunfardo define esta palabra como:

Ayuda que se presta desinteresadamente. // Favor solidario. // Auxilio generoso. (Espíndola, 2002: 243-244).

\footnotetext{
${ }^{12} \mathrm{http}: / /$ es.wiktionary.org/wiki/chau

${ }^{13} \mathrm{http} / / /$ buscon.rae.es/draeI/SrvltConsulta?TIPO_BUS=3\&LEMA=chau html

${ }_{14} \mathrm{http}: / /$ www.carretes.cl/fiestas-psu/2008-12-02-Fiesta-Chau-PSU-en-Espacio-Riesco-14674.

${ }^{15} \mathrm{http} / / /$ www.lacuarta.cl/diario/2007/06/24/24.10.4a.CRO.CUADERNOS.html 24 de junio de 2007.
} 
El Nuevo diccionario lunfardo, por su parte, indica:

V. Gaucho: Gauchada: colectividad de los gauchos (...); favor que se brinda generosamente y sin esperar recompensa alguna (Gobello, 1999: 128).

El DRAE confirma su presencia en Argentina, entre otros países:

1. f. Am. Mer. y C. Rica. Servicio o favor ocasional prestado con buena disposición.

2. f. Arg. p. us. Acción propia de un gaucho.

3. f. Guat. Acción taimada, disimulada.

En Wikcionario se dan más antecedentes ${ }^{16}$ :

frase "hacer una gauchada", totalmente opuesta a "hacer una guachada"significa tener un gesto de hidalguía o una buena actitud" (en Gaucho).

Los siguientes titulares extraídos de la prensa nacional confirman su presencia en el español de Chile:

Las gemelas se convirtieron en las primeras niñas apadrinadas por un presidente chileno, y mujer más encima. Aprovechando la gauchada de la Presi $[\ldots]^{17}$

Como no lo consiguió por las suyas, pidió a un amigo que le hiciera la gauchada, exhibiéndola en Portalnet.cl ${ }^{18}$

\section{4) $\operatorname{Goma}(s)$}

El Diccionario del lunfardo define esta palabra como:

p. Humoríst. Senos de la mujer, en comparación con las pelotas de goma. (Espíndola, 2002: 249).

El Nuevo diccionario lunfardo, por su parte, indica:

\footnotetext{
${ }^{16}$ http://es.wiktionary.org/wiki/Especial:Buscar/gauchada?search=gauchada\&go=Ir

${ }^{17} \mathrm{http} / / /$ cuarta.cl/diario/2006/10/27/27.02.4a.CRO.GEMELAS.html 27 de octubre de 2006

${ }^{18}$ http://www.lacuarta.cl/contenido/63_35494_9.shtml 24 de noviembre de 2009.
} 
[...]// En pl., pechos [...]. (Gobello, 1999: 130).

Consigna, también, la presencia de esta palabra en un sainete de Eduardo Pérsico (El olvido está en libertad) editado en 1986: “[...] de buen lomo y henchidas gomas $[\ldots]$..19.

Este término -con el significado que nos ocupa- no se consigna en el $D R A E$, ni en Wikcionario. Sin embargo, su uso hoy en Chile es evidente, como lo comprueban los siguientes ejemplos extraídos de la prensa nacional:

La showoman desea volver a las pistas con tutti y por eso que se está enchulando de pies a cabeza. Marlen quiere matarle el punto a Lucy Salazar: Se puso así unas gomas ${ }^{20}$

Tengo claro que no me dan pega porque no tengo gomas de plástico, ja ja. (Entrevista a Marcela Osorio) $)^{21}$

\section{5) Manga}

El Diccionario del lunfardo define esta palabra como:

//Cantidad numerosa de personas, animales o cosas. Una manga de fanáticos. Una manga de problemas. (Espíndola, 2002: 307).

El Nuevo diccionario lunfardo, por su parte, indica:

Pop. Conjunto de personas [...]. Tiene connotación despectiva y procede del argent. manga de langostas: nube de langostas, proveniente a su vez del cast. manga: partida o destacamento de tropa. (Gobello, 1999: 165).

Es interesante que en un tango de 1933 (Pipistrela, de Fernando Ochoa) ${ }^{22}$ ya se utilizaba esta palabra:

\footnotetext{
${ }^{19}$ Cabe destacar que esta fecha, no obstante parecer reciente, es anterior a aquella en que esta palabra se populariza en Chile (no antes del último decenio).

${ }^{20} \mathrm{http}: / /$ www.lacuarta.cl/diario/2007/07/26/26.19.4a.ESP.MARLEN.html 26 de julio de 2007.

${ }^{21} \mathrm{http} / /$ www.lacuarta.cl/diario/2004/03/12/12.03.4a.ESP.MARCELA.html 12 de marzo de 2004.

${ }^{22}$ Tango disponible en: http://www.todotango.com/spanish/las_obras/Tema.aspx?id=Q36 Pa7QeOA4=
} 
[...] Yo quisiera tener mucho vento / Pa' comprarme o sombrero y zapato / Añaparme algún coso del centro / Pa' dejar esta manga de patos $[\ldots]$.

El DRAE consigna su presencia en Argentina y Uruguay, entre otros países sudamericanos, pero no en Chile:

19. f. despect. coloq. Arg., Bol. y Ur. Grupo de personas. Una manga de atorrantes $^{23}$

Sin embargo, los siguientes ejemplos extraídos de la prensa nacional confirman su difusión en el español de Chile actual:

-[...] quien hizo una performance para ser fotografiada en una tarima, donde desde abajo una manga de babosos la miraban con la boca más abierta que pesca' $\mathrm{o}^{24}$

-La manga de califas aprovechaba de tomar fotos desde abajo $[\ldots]^{25}$

6) $M u f a$

El Diccionario del lunfardo define esta palabra como:

Lunf. [...] Mala suerte. Yeta. Ando con la mufa: todo me sale mal [...]. (Espíndola, 2002: 335).

El Nuevo diccionario lunfardo, por su parte, indica:

Lunf. [...] Mala estrella, mala suerte (especialmente entre los jugadores) [...]. (Gobello, 1999: 175).

Consigna, también, la presencia de esta palabra en un relato de 1947 (Andanzas de Juan Mondiola, de Miguel Ángel Bavio Esquiú, p. 86):

\footnotetext{
${ }^{23} \mathrm{http}$ //buscon.rae.es/draeI/SrvltConsulta?TIPO_BUS=3\&LEMA=manga

${ }^{24}$ http://www.lacuarta.com/diario/2006/07/02/02.22.4a.ESP.COLALESS.html 2 de julio de

${ }^{25}$ http://www.lacuarta.cl/diario/2006/07/02/02.22.4a.ESP.COLALESS.html 2 de julio de 2006.
} 2006. 
[...] Hay que andar perseguido por los canes para que en tres horas de escolaso no se haya dado el 30 más que una sola vez. Y de la tercera decena me cantaban uno a las perdidas. ¡Flor de mufa!

En Wikcionario se dan más antecedentes ${ }^{26}$ :

Transmitir mala suerte a alguien o algo.

Uso: Lunfardismo

Ámbito: Rioplatense

El DRAE consigna su presencia en Argentina y Uruguay, pero no en Chile:

2. f. coloq. Arg. y Ur. Enfado o malhumor por algo que molesta. ${ }^{27}$

Sin embargo, los siguientes ejemplos extraídos de la prensa nacional confirman su difusión en el español de Chile actual:

-Suazo mató la mufa y logró celebrar con el Zaragoza ${ }^{28}$

-[...] el equipo de Héctor Pinto logró romper la mufa de nueve partidos sin ganarle al rojo $[\ldots]^{29}$

7) (Un) Palo

El Diccionario del lunfardo define esta palabra como:

p. Un millón de pesos.// Palo verde. Un palo verde. Un millón de dólares. (Espíndola, 2002: 352).

El Nuevo Diccionario Lunfardo, por su parte, indica:

Pop. Millón de pesos. ("Sabes cuánto pagó? Palo y medio, pibe". Benítez de Castro, Sexy-Bar, 293) [...]. (Gobello, 1999: 191).

\footnotetext{
${ }^{26} \mathrm{http}: / /$ es.wiktionary.org/wiki/mufar

${ }^{27} \mathrm{http}: / /$ buscon.rae.es/draeI/SrvltConsulta?TIPO_BUS=3\&LEMA=mufa

${ }^{28} \mathrm{http}: / /$ www.cronica.cl/noticias/site/artic/20100131/pags/20100131150550.php 31 de enero

${ }^{29}$ http://www.lacuarta.com/diario/2004/12/06/4ta.12.DEP.UNION.html 6 de diciembre de
} de 2010. 2004. 
Se agrega, además, un dato importante: "Acepción de origen incierto, aparecida a fines de la década de $1950 "$.

En Wikcionario se dan más antecedentes ${ }^{30}$ :

Un millón, en especial hablando de dinero Ámbito: Cono Sur

Uso: Coloquial

Ejemplo: "De todos modos, no es Kirchner quien le paga al Fondo; los diez mil palos verdes los ponemos los trabajadores." Kirchner cumple (con el FMI), sitio del Partido Obrero de Argentina.

En el DRAE no se consigna esta palabra con el significado que nos ocupa.

Los siguientes ejemplos extraídos de la prensa nacional confirman su difusión en el español de Chile actual:

-En 3,5 palos quedó sueldo de Presidente ${ }^{31}$

-HOTEL 7 ESTRELLAS OFRECE JORNADA DE LUJO POR UN PALO VERDE $^{32}$

\section{8) Pendejo/ pendex}

El Diccionario del lunfardo define esta palabra como:

Niño, pebete, chico, púber [...] Del esp. pendejo: pelo que nace entre las ingles. Alude a la pequeñez de estos pelos. (Espíndola, 2002: 377).

Consigna, también, la presencia de esta palabra en los versos de un poema que data de 1928 (Cacho de recuerdo, de Carlos de la Púa):

[...] Compañera buena que engrupí pendejo / mujercita gaucha, que nunca fayó / la que tenía en los ojos un dejo / de esa tristeza que hoy tengo yo $[\ldots]$

${ }^{30} \mathrm{http}: / /$ es.wiktionary.org/wiki/palo

${ }^{31} \mathrm{http} / /$ www.lacuarta.com/diario/2002/11/23/23.06.4a.CRO.GOBIERNO.html 23 de noviembre de 2002

32 http://www.lacuarta.cl/noticias/vuelta-al-mundo/2010/02/66-71221-9-hotel-7-estrellasofrece-jornada-de-lujo-por-un-palo-verde.shtml 8 de febrero de 2010. 
El Nuevo diccionario lunfardo, por su parte, indica:

Pop. Púber ("Enrique Amorim era, hasta los cuarenta y siete o cuarenta y ocho años[...] un muchacho. Más todavía, como solía yo decirle, un pendejo". Gálvez, En el mundo..., 297). Del cast. pendejo: pelo que nace en el pubis y en las ingles. Pendejada: chiquillada. (Gobello, 1999: 198).

El DRAE consigna su presencia en Argentina y Uruguay, pero no en Chile:

7. m. vulg. Arg. y Ur. Chico, adolescente ${ }^{33}$

Sin embargo, los siguientes ejemplos extraídos de la prensa nacional confirman su difusión en el español de Chile actual:

-Soy un weón de clase media, vividor de pendejo y nadie me ha regalado nada ${ }^{34}$

-El asalto a la dama de 88 años ocurrió el viernes 29 de julio en Miraflores con Merced, en pleno centro de Santiago. El pendejo intentó arrebatarle su pirula cartera $[\ldots]^{35}$

\section{9) Punga}

El Diccionario del lunfardo define esta palabra como:

Lunf. Y l. del. Hurto de dinero o efectos de los bolsillos de las personas.// Ladrón que se dedica a cometer esta clase de robo. Espíndola alude también a que el punga es un ladrón que se siente artista y sobre los demás ladrones comunes, pues necesita de mucha delicadeza para robar metiendo sus manos en los bolsillos de las víctimas [...]. (Espíndola, 2002: 409-410).

El Nuevo diccionario lunfardo, por su parte, indica:

Lunf. Ladrón, especializado en hurtar el dinero o los objetos que la víctima lleva en sus bolsillos. Del ital. merid. punga: bolsillo[...]. (Gobello, 1999: 211).

\footnotetext{
${ }^{33} \mathrm{http}: / /$ buscon.rae.es/draeI/SrvltConsulta?TIPO_BUS=3\&LEMA=pendejo

${ }^{34} \mathrm{http}: / /$ lacuarta.cl/diario/2005/05/20/20.06.4a.ESP.DANIEL.html 20 de mayo de 2005.

${ }^{35} \mathrm{http}: / /$ www.lacuarta.cl/diario/2007/08/04/04.06.4a.CRO.CUMA.html 4 de agosto de 2007.
} 
Es interesante que en un tango del año 1926 (El ciruja, de Francisco Alfredo Marino $)^{36}$ ya se utilizaba esta palabra:

[...] Recordaba aquellas horas de garufa / cuando minga de laburo se pasaba / meta punga al codillo escolaseaba / y en los burros se ligaba un metejón / cuando no era tan junado por los tiras / la lanceaba sin temer el manyamiento / una mina le solfeaba todo el vento y jugó con su pasión $[\ldots]$.

El DRAE consigna su presencia en Argentina y Chile:

2. com. coloq. Arg. y Chile, ladrón (persona que hurta o roba). ${ }^{37}$

En Wikcionario se dan más antecedentes ${ }^{38}$ :

Ladrón que se especializa en birlar objetos sin violencia del bolsillo o bolso de su víctima.

Ámbito: Rioplatense

Uso: Lunfardismo

Sinónimos: carterista (España)

Ejemplo: "Están ahí, pero no los ves. De eso se trata. Están pero no están. Así que cuidá el maletín, la valija, la puerta, la ventana, el auto. Cuidá los ahorros, cuidá el culo. Porque están ahí, van a estar siempre ahí. Chorros. No, eso es para la gilada. Son descuidistas, culateros, abanicadores, gallos ciegos, biromistas, mecheras, garfios, pungas, boqueteros, escruchantes, arrebatadores, mostaceros, lanzas, bagalleros, pesqueros. Filos". Marcos (Ricardo Darín), en Nueve reinas (2000) [película], de Fabián Bielinsky.

Los siguientes ejemplos extraídos de la prensa nacional confirman su difusión en el español de Chile actual:

-Pillaron a punga justo antes del asalto ${ }^{39}$

-Punga agilao quiso robar cartera a amiga de su polola ${ }^{40}$

\footnotetext{
${ }^{36}$ Tango disponible en: http://www.todotango.com/spanish/las_obras/Tema.aspx?id= QWZB5iNkOtQ=

${ }^{37} \mathrm{http}: / /$ buscon.rae.es/draeI/SrvltConsulta?TIPO_BUS=3\&LEMA=punga

${ }^{38} \mathrm{http}$ ///es.wiktionary.org/wiki/punga

${ }^{39} \mathrm{http} / / /$ www.cronica.cl/noticias/site/artic/20091122/pags/20091122202701.php

40 http://www.lacuarta.cl/diario/2007/01/13/13.06.4a.CRO.PUNGA.html 13 de enero de 2007.
} 
10) Tira

El Diccionario del lunfardo define esta palabra como:

Lunf. Agente de investigaciones de la policía que viste de civil. // Policía secreta [...]. (Espíndola, 2002: 473).

El Nuevo diccionario lunfardo, por su parte, indica:

Lunf. Agente de la policía de investigaciones que viste habitualmente de civil. ("La patota de tiras husmea como los perros atraillados cuando ventean la casa”. Arlt, Aguafuertes..., 125) [...]. (Gobello, 1999: 243).

Se agrega, además, un dato relevante: “[...] del italiano jergal tira: espía de la policía”.

En el DRAE no se consigna esta palabra con el significado que nos ocupa.

En Wikcionario se dan más antecedentes ${ }^{41}$ :

En general, agente de la policía u otra fuerza de seguridad

Uso: Lunfardismo

Ámbito: Rioplatense

Sinónimos: azul, botón, cana, rati, yuta

Funcionario de la policía civil de investigaciones

Uso: Coloquial

Ámbito: Chile

Sinónimos: rati

Hiperónimo: detective

Los siguientes ejemplos extraídos de la prensa nacional confirman su difusión en el español de Chile actual:

-Siempre ha sido igual, acá en nuestra ciudad todos se acuerdan del famoso Pato Pérez, ese tira sí que era coimero y sinvergüenza, compraba autos que no pagaba, pedía cheques prestados que tampoco pagaba y además cobraba su comisión por la pasada... lo "invitaron" a jubilar cuando coimió/trabajó 20 años. Josep, La Unión ${ }^{42}$

\footnotetext{
${ }^{41}$ http://es.wiktionary.org/wiki/tira

${ }^{42} \mathrm{http} / /$ www.lanacion.cl/prontus_noticias_v2/site/artic/20090127/pags/20090127235513html 28 de enero de 2009.
} 
-EL NEGOCIO DE LOS TIRAS. Ricardo Flores, el defensor público a cargo de la defensa de Margarita Cuadro Aedo y de algunos detectives envueltos en el mismo caso, afirma que "nuestros policías han estado siempre más cerca de Sturky y Hutch que de CSI" ${ }^{33}$

\section{ALGUNAS CONSIDERACIONES RESPECTO DEL CORPUS PRESENTADO}

Se puede observar que las palabras presentadas son de uso frecuente en Chile y no parte de un léxico especializado o restringido. Esta cotidianeidad, sin embargo, no está en una proporcionalidad directa con el grado de consciencia que el chilenohablante tiene de su estatus de argentinismos/ lunfardismos. Por ejemplo, no parece ser de dominio general que palabras tan frecuentes como "gomas" (senos) o "(un) palo" ((un) millón) provienen de Argentina. No obstante, como hemos visto, la plausibilidad de que así sea es altísima. Es el caso también de la popular palabra de despedida "chau", con el añadido de que en ella esta plausibilidad se ve reforzada por su origen en el dialecto genovés.

Por otro lado, las palabras presentadas ocurren en el habla coloquial, lo cual resulta altamente relevante, pues, como ha establecido la interdisciplina sociolingüística, es esta variedad de habla la que nos informa acerca de posibles cambios lingüísticos en curso (Silva-Corvalán, 2001: 25).

$\mathrm{Al}$ observar las palabras analizadas, cabe también preguntarse si la influencia descrita se verifica sólo en la lengua o es una manifestación de un fenómeno cultural más generalizado. Sobre este punto, Salamanca (2010: 141) sostiene que "[...] la permeabilidad que el español de Chile exhibe en relación con el español de Argentina está en consonancia con una permeabilidad cultural más amplia". Este autor menciona como ejemplos el saludo -o despedida- con un beso en la mejilla entre hombres (especialmente deportistas) y cierta gestualidad que indica extrañeza, costumbres de larga data en Argentina y de reciente incorporación en Chile. A estas evidencias debemos agregar algunos hábitos adquiridos también recientemente por los chilenos, como la realización de asados, en ambientes urbanos, los fines de semana, costumbre que en Argentina tiene un arraigo de mucho más larga data. Por supuesto, cabe también la posibilidad de considerar que este hábito es producto de un desarrollo independiente en

${ }^{43} \mathrm{http} / / /$ www.theclinic.cl/2008/11/21/el-mercado-negro-del-sistema-judicial/comment-page-2/ 21 de noviembre de 2008. 
Chile. Sin embargo, nos parece que proponer una influencia con una clara direccionalidad es una hipótesis plausible si se considera, por ejemplo, que un ingrediente inexcusable en esa instancia en Chile es el etiquetado con la palabra "choripán", cuya composición léxica (la palabra "chorizo", más la palabra "pan") nos remite directamente a un elemento típico de la tradición culinaria transandina (el chorizo).

Otro aspecto donde se puede apreciar esta influencia cultural más amplia es en la incipiente difusión de la celebración del cumpleaños número quince ${ }^{44}$, especialmente en adolescentes de estrato alto, de sexo femenino. Esta costumbre, que no sólo está presente en los países del Río de la Plata, es altamente probable que se esté traspasando a Chile desde el otro lado de Los Andes y reforzando a través de programas de televisión por cable, dedicados a adolescentes, donde se exhiben estos festejos.

Aunque más específico, otro ámbito donde es posible constatar esta influencia es el futbolístico (especialmente en el perfil que ostentan los seguidores más incondicionales de los clubes (los barras bravas)). Por ejemplo, los gritos/cánticos y ademanes de los hinchas chilenos, claramente remiten a los que caracterizan a sus pares trasandinos.

Un ámbito en el cual, por razones de acceso, es difícil constatar esta influencia, pero donde todo parece indicar que se sigue produciendo de manera consistente, es el delictivo. Algunas de las palabras que están en nuestro corpus (punga, por ejemplo) confirman esta conexión histórica. Sin embargo, se precisa de un trabajo actualizado en este ámbito para hacer afirmaciones más categóricas con respecto a su alcance en el presente.

A la luz de estas consideraciones, no parece una extrapolación delirante contemplar la posibilidad de que en un futuro beber mate en lugares públicos o desplazar el acento a la última sílaba en el imperativo verbal (como en "cantá", "corré", "vivî") o en construcciones más complejas (como en "buscandoló", "diciendolé") sean parte del repertorio de costumbres nacionales y no una conducta de lesa chilenidad, como podrían ser consideradas hoy.

\section{CONCLUSIONES}

En esta sección entregamos algunas reflexiones con respecto al alcance de nuestro trabajo y las proyecciones del mismo.

\footnotetext{
${ }^{44}$ Expresiones como "voy a un cumple de 15", "los 15 de fulana", "mis 15", son expresiones habituales en el Río de La Plata y que ya se comienzan a escuchar en Chile.
} 
En relación con lo primero, destacamos que, no obstante parecernos justificado utilizar la simetría en forma y significado de las palabras como uno de los criterios centrales para la asignación de estatus de argentinismo, también se debe prestar atención a aquellas palabras que: a) tienen identidad en la forma, pero sólo proximidad en el contenido; b) tienen identidad en el contenido, pero (sólo) proximidad en la forma, y c) tienen identidad en forma y contenido, pero no es posible estimar con una alta plausibilidad que su uso en Chile es posterior al de Argentina. Por ejemplo, son sugerentes las coincidencias en palabras como "chucheta" (con simetría en la forma, pero sólo proximidad en el significado) o "fifí" (con simetría en la forma y el significado, pero de alcance restringido). Tampoco se debe descartar la posibilidad de que palabras tan arraigadas en el léxico coloquial chileno como "pato" (en el sentido de 'carente de dinero') o "flaite" provengan de Argentina. Sobre esta última palabra, es interesante considerar que el Nuevo diccionario lunfardo consigna como una de sus entradas, el lema feite y lo define como una "Herida en el rostro. || Cicatriz de una herida recibida en el rostro ('...canero viejo y caficio / con un feite en el escracho', Fernández, Versos..., 57). También corre faite ${ }^{45}[\ldots]$ ”. (Gobello, 1999: 115). Es interesante que un tango de 1925 consigna la palabra feite ${ }^{46}$ :

El dorima que te echaste, con un feite en el escracho, cada vez que está borracho la presume de matón. Y es un ñorse tan amargo, que una noche en la cortada lo asustó con la parada hasta el loco Napoleón. No podés meter la mula, son al cohete tantas mañas.

Como se ve, aún hay muchos aspectos que considerar en el tema que nos ocupa. Para avanzar en él y afianzar la convicción con respecto al estatus de estas palabras (chilenismo importado por el léxico del español de Argentina, argentinismo importado por el léxico del español de Chile, o chilenismo y argentinismo a la vez, pues son producto de desarrollos independientes) es deseable focalizar este fenómeno desde otras perspectivas disciplinarias que contribuyan con sus respectivos andamiajes teórico-metodológicos. En nuestro caso, consideramos que hemos situado en la discusión académica

\footnotetext{
${ }^{45}$ Uno de los autores de este artículo tuvo la oportunidad de escuchar en su adolescencia a algunos sujetos que conocían y utilizaban la coa (jerga usada por la gente del hampa en Chile), quienes empleaban con frecuencia el término "faite" para referirse a un individuo, también delincuente, que causa molestia.

${ }^{46}$ Tango disponible en: http://www.todotango.com/spanish/las_obras/Tema.aspx?id=KNDR $\operatorname{moK} 31 \mathrm{Yc}=$
} 
un tema relevante que, desde un punto de vista teórico, puede dar luces con respecto a los procesos sociolingüísticos que controlan la instalación de parte del léxico de una variante de una lengua en otra; junto con proveer más evidencias para sustentar la tesis de la permeabilidad cultural chilena ${ }^{47}$ y perfilar el estudio de la influencia desde Argentina -en el plano cultural, en general; y lingüístico, en particular- como una línea de investigación.

Una proyección que se sigue como una secuencia "natural" de este trabajo es la ampliación del número de palabras consideradas y la pesquisa de expresiones más extensas. Entre estas últimas, estimamos que se debe estudiar con particular atención expresiones como sí o sí (como en "lo haré sí o sî"), de una (como en "el problema se resolvió de una"), al toque (como en "al toque nos dimos cuenta de lo que pasaba"), loco lindo (como en "es un loco lindo"), dar bola (como en "no me dieron bola"), de aquellos (como en "el anterior fue un campeonato de aquellos"), no es menor (como en "eso no es menor"), en una de esas (como en "en una de esas ganamos el campeonato"), ya fue (como en "fue difícil, pero ya fue"), comprar(sela) (como en "me dijo eso, pero yo no se la compré"), ir por más (como en "ahora vamos por más!"), pero bueno (como en "las cosas no han resultado, pero bueno"), pues hay fundadas razones para sostener que constituyen argentinismos presentes en el habla coloquial chilena ${ }^{48}$.

Finalmente, expresamos nuestra coincidencia con lo señalado por Salamanca (2010) en cuanto a que no es poco probable que este fenómeno de argentinización se afiance en Chile. Esto, claro está, y como expone este autor, en el entendido de que se tiendan a mantener ciertas condiciones histórico-culturales en nuestro país y en el país transandino. Por ejemplo, la reputación artística (en el más amplio alcance de esta última palabra) y deportiva (especialmente futbolística), etc., que han hecho y que hacen de Argentina una nación prestigiosa y referencial para un chilenohablante ${ }^{49}$.

\section{REFERENCIAS}

Arlt, R. (1933). Aguafuertes porteñas. Buenos Aires: Sudamericana. Bavio Esquiú, M. Á. (1947). Andanzas de Juan Mondiola. Buenos Aires: Elio.

\footnotetext{
${ }^{47}$ Permeabilidad que, sin embargo, no es absoluta, pues se verifica sólo con respecto a aquellas variantes consideradas prestigiosas.

${ }^{48}$ Actualmente, uno de los autores de este artículo supervisa una investigación en que se considera el análisis de estas expresiones. Aquí, por supuesto, la metodología ha variado, pues la mayoría de estas expresiones no constituyen entradas de diccionarios.

${ }^{49}$ Aunque esto último pueda negarse en el nivel retórico.
} 
Benítez de Castro, C. (1973). Sexy Bar. Barcelona: Círculo de Lectores. Espíndola, A. (2002). Diccionario del lunfardo. Buenos Aires: Planeta.

Fernández, F. (1916). Versos rantifusos. Buenos Aires.

Gálvez, M. (1961). En el mundo de los seres ficticios. Buenos Aires: Hachette.

Gobello, J. (1999). Nuevo diccionario lunfardo. Buenos Aires: Corregidor.

Gómez Bas, J. (1965). La comparsa. Buenos Aires: Falbo.

Pérsico, E. (1986). El olvido está en libertad. Buenos Aires: Futuro.

Púa, C. de la [Carlos Raúl Muñoz y Pérez] (1928). La crencha engrasada. Buenos Aires: Trazo.

Real Academia Española de la Lengua (2009). Diccionario. Versión on line disponible en <http://www.rae.esl>.

Sáez, L. (1999). El español de Chile en las postrimerías del siglo XX. Santiago: Universidad de Santiago.

(2000). Cómo hablamos en Chile. Ocho aproximaciones. Santiago: Sociedad Chilena de Lingüística - Bachillerato en Ciencias y Humanidades (USACH).

Salamanca, G. (2010). “Apuntes sociolingüísticos sobre la presencia de argentinismos en el léxico del español de Chile”. Atenea 502, 125-149.

Salas, A. (1992). "El componente indoamericano en la identidad sociocultural chilena. Una presentación etnolingüística”. Acta Literaria 17, 11-24.

(1996). "Aymara mapuche ¿lenguas o dialectos? En torno a la valoración social de los vernáculos chilenos”. Atenea 473, 25-37.

San Martín, A. (2011). "Voces del lunfardo en el registro festivo del diario chileno La Cuarta”. Onomázein 23(1), 105-147.

Silva-Corvalán, C. (2001). Sociolingüística y pragmática del español. Washington D.C.: Georgetown University Press.

Verbitzky, B. (1953). Calles de tango. Buenos Aires: Vorágine. 